\title{
Determination of phosphorylation and deprotonation induced higher order structural transitions in $\alpha_{\mathrm{s}}$-caseins
}

\author{
Ilokugbe Ettah and Lorna Ashton* \\ Department of Chemistry, Lancaster University, Lancaster, Lancashire LA1 4YB, UK \\ * Correspondence: I.ashton@lancaster.ac.uk
}

\begin{abstract}
One extremely sensitive and highly successful application of Raman spectroscopy is the structural characterisation of proteins Understanding higher order structure and its effect on protein stability is essential not only for biopharmaceutical and food manufacturing but also for the understanding of diseases that result from the misfolding of proteins including diabetes type II, Alzheimer's and Parkinson's disease. Due to the large amount of structural information available in Raman spectra, even small alterations in protein conformations including increased exposure of binding regions or changes in geometry of secondary structural elements can be identified. In this study, we demonstrate the unique sensitivity of Raman spectroscopy to subtle structural transitions in an intrinsically open, flexible protein, $\alpha_{s}$-casein, in response to phosphorylation and deprotonation. Through the application of 2D correlation analysis two separate transition phases have been identified from $\mathrm{pH}$ 6-9 and $\mathrm{pH} 10-12$ for both phosphorylated and dephosphorylated $\alpha_{\mathrm{s}}$-casein. However, the actual structural changes observed in each $\mathrm{pH}$ range differed considerably between the phosphorylated and dephosphorylated $\alpha_{s}$-casein. Furthermore, the presence of the phosphorylated serine residues is demonstrated to have a shielding effect during deprotonation of the protein.
\end{abstract}


Proteins, including enzymes, antibodies and transport molecules, are not only essential for maintaining health, but also play an important role in biopharmaceutical and food manufacture. However, regardless of the role they play proteins will only function optimally when in the correct structural conformation and devastating effects can occur as a result of protein misfolding, for example diseases such as Alzheimer's, Parkinson's, diabetes Type II and atherosclerosis all result from misfolded proteins forming amyloid fibril plaques. ${ }^{1}$ Maintaining the correct fold is also essential for protein based therapeutics and in food manufacturing if protein activity is to be preserved throughout production and storage..$^{2-4}$ Even small changes in conformation that occur as a result of post-translational modifications (PTM) and variations in preparation and formulation, including $\mathrm{pH}$, can affect protein stability and function. Consequently, there is a need for analytical methods that can identify subtle changes in conformation and stability throughout the manufacturing processes. Raman spectroscopy provides an ideal analytical tool to assess changes in the higher order structure and stability of proteins. The technique is non-destructive, rapid, can be applied to low and high concentrations of samples and as water is a weak Raman scatterer it can be applied to proteins in aqueous conditions.

Phosphorylation is an important PTM, which effects protein conformation and stability. The phosphorylation of a protein by a kinase, or dephosphorylation by a phosphatase can play an essential role in cellular processes. ${ }^{5,6}$ In particular, the heavily phosphorylated casein proteins, act as both storage and transport molecules for calcium in the mammary glands but also act as protecting agents against amyloid formation during self-association of individual caseins..$^{7-9}$ Due to the difficulties in crystallising caseins they were all initially thought of as random coil or intrinsically denatured proteins, however, a range of spectroscopic studies have identified the presence of secondary structural elements including $\alpha$-helix, $\beta$-sheet, turns, and polyproline II (PP-II) confirmation, although the exact percentage content of each is still to be unequivocally determined.

7, 9-12 Despite the existence of such structural elements, caseins do not form globular conformations but remain in more open and flexible forms. ${ }^{7,9}$ This open and more flexible structure of caseins compared to other proteins is attributed to the high content of proline residues and high surface hydrophobicity $7,8,11$ and whilst this offers some flexibility in the protein conformation maintaining protein stability and the correct fold is still essential for protein function. Studies of the individual caseins suggest that $\alpha_{s 1-}$ and $\beta$-casein play an important role in preventing protein misfolding and amyloid formation in $\alpha_{\mathrm{s} 2}$ and k-caseins, respectively, during self-assembly and aggregation in the absence of calcium. ${ }^{7-9}$ In this study, we have compared $\mathrm{pH}$-induced structural changes in bovine $\alpha_{\mathrm{s}^{-}}$ casein (a mix of the two $\alpha_{\mathrm{s}^{-}}$and $\alpha_{\mathrm{s2}}$ - components at a 4:1 ratio in bovine milk) in both the phosphorylated and dephosphorylated forms to investigate important changes in protein conformation that result from deprotonation and phosphorylation using Raman spectroscopy and 2D correlation analysis.

\section{Experimental}

\section{Data collection}

Samples of phosphorylated and dephosphorylated $\alpha_{\mathrm{s}}$-casein from bovine milk were purchased from Sigma Aldrich and used without further purification. Separate samples were prepared at different $\mathrm{pH}^{\prime} \mathrm{s}$ in the $\mathrm{pH}$ range 5.7 to 12.3 at concentrations of $10 \mathrm{mg} / \mathrm{mL}$, to ensure full deprotonation of the 
protein. The dry material was dissolved in deionised water and $\mathrm{pH}$ was adjusted using dilute $\mathrm{NaOH}$ or $\mathrm{HCl}$. The $\mathrm{pH}$ of each sample was measured using a pH meter (HI2210) by Hanna Instruments $( \pm \sim 0.5)$. For the phosphorylated $\alpha_{s}$-casein sample $\mathrm{pH}$ values of $5.7,6.5,7.7,8.7,9.2,10.2,11.1$ and 12.1 were recorded and for the dephosphorylated $\alpha_{s}$-casein $\mathrm{pH}$ values of $6.1,7.0,7.6,8.9,10.1,11.7$ and 12.3 were recorded. Native samples (samples without any adjustment of $\mathrm{pH}$ ) were recorded at $\mathrm{pH} 6.5$ for phosphorylated $\alpha_{\mathrm{s}}$-casein and pH 7.0 for dephosphorylated $\alpha_{\mathrm{s}}$-casein. $400 \mu \mathrm{L}$ of each solution was pipetted into a quartz 96 -well plate before spectral collection. All Raman measurements were performed using a confocal Raman system (inVia, Rensihaw plc, Wotton-Under Edge, UK) coupled to a $785 \mathrm{~nm}$ wavelength laser, x15 objective and $1200 \mathrm{~mm}$ grating. Spectra were acquired for 10s exposure with 180 accumulations (total collection time 30 minutes) with a laser power at sample of $\sim 30 \mathrm{~mW} .3$ repeat spectra were collected for each $\mathrm{pH}$ and then averaged for data analysis.

\section{D correlation spectroscopy (2DCOS)}

2DCOS is a cross-correlation technique, which can be applied to a set of perturbation-induced spectra as a function of two independent wavenumber positions. The acquired data set (ordered in the direction of relatively consistent perturbation-induced changes) forms an experimental matrix to which the cross-correlation function is applied resulting in a new set of matrices improving visualization and therefore interpretation of the spectral variations. ${ }^{4,13,14}$ Synchronous matrices identify similarities in behaviour, whilst asynchronous matrices identify differences in behaviour between data points at two independent wavenumbers. Autocorrelation plots display significantly varying peak intensities (identified in the synchronous matrix) from which the overall extent of intensity changes of individual bands can be determined and compared. Perturbation correlation moving windows (PCMW) matrices relate the spectral variations to the specific perturbation values identifying distinct phases in behaviour. ${ }^{4,13,14}$

As has been extensively discussed in previous papers, appropriate data preprocessing is necessary to generate reliable and clear 2DCOS plots, particularly with biological samples. ${ }^{15,16}$ For the Raman spectra presented here solvent extraction, normalisation to the intensity invariant Raman band measured at $\sim 1450 \mathrm{~cm}^{-1}$ (arising from methylene deformations), baseline subtraction and smoothing were all carried out in MATLAB software (version R2016a) using an in-house toolbox. Interpolation was also applied to the 2DCOS data sets before calculation of 2DCOS matrices. Full details of all data processing approaches are available in Supplementary Information).

\section{Results and Discussion}

\section{Comparison of phosphorylated and dephosphorylated $\alpha_{s}$-casein}

Figure 1 compares the Raman spectra of the phosphorylated and dephosphorylated forms of $\alpha_{s^{-}}$ casein where numerous Raman features assigned to amino acid residues and secondary structure can clearly be observed (Table 1). As previously reported by Jarvis et al. ${ }^{17}$ who successfully quantified casein phosphorylation using Raman spectroscopy, the two spectra are very similar with only minimal intensity differences between the phosphorylated and dephosphorylated forms of $\alpha_{s^{-}}$ casein. In Figure 1 the bands assigned to side chain residues at $1003 \mathrm{~cm}^{-1}$ (Phe), ${ }^{18,19} 850 / 830 \mathrm{~cm}^{-1}$ 
(Tyr Fermi Doublet) ${ }^{20,21}$ and $755 \mathrm{~cm}^{-1}(\operatorname{Trp})^{22,23}$ as well as bands assigned to secondary structure at $1667 \mathrm{~cm}^{-1}$ ( $\beta$-sheet), ${ }^{24} 1337 \mathrm{~cm}^{-1}$ ( $\alpha$-helix / Trp), ${ }^{25,26} 1318 \mathrm{~cm}^{-1}\left(\alpha\right.$-helix) ${ }^{15,26}$ and $1250 \mathrm{~cm}^{-1}$ (disordered $)^{15,27}$ can all be observed to have a slightly higher intensity in the phosphorylated spectrum compared to the dephosphorylated spectrum. The decrease in Raman spectral intensity has previously been attributed to a loss of structure and a change in solvent exposure of the aromatic amino acids. ${ }^{17,28}$ In particular, the significant difference in intensity and bandwidth at 1003 $\mathrm{cm}^{-1}$ was identified as an important feature in the calibration method used to quantify phosphorylation. ${ }^{17}$

However, previous studies using $C D$ and fluorescence spectroscopy to measure secondary structural differences between phosphorylated and dephosphorylated $\alpha_{s}$-casein could not identify any differences in secondary structure and in fact an increase in secondary structure in the dephosphorylated form has also been suggested. ${ }^{8}$ Raman bands can arise specifically from side chain orientation as well as the quantity of amino acids and secondary structure and therefore changes observed in the Tyr and Trp Raman bands at 755, 850/830 and $1337 \mathrm{~cm}^{-1}$ can be associated with changes in side chain orientation and/or solvent exposure (Table 1). Variations in the wavenumber position of $\alpha$-helical assigned bands in the region of $1315-1345 \mathrm{~cm}^{-1}$ have also been associated with subtle changes in $\alpha$-helical symmetry ${ }^{25}$ and again, it may be these changes rather than a distinctive loss of secondary structure that is being detected by the spectral variations observed in Figure 1. Importantly, in Figure 1 there are several Raman bands with the same intensity and position regardless of whether $\alpha_{s}$-casein is phosphorylated or not including Raman bands observed at 1615 , $1208,1173,1124$ and $930 \mathrm{~cm}^{-1}$.

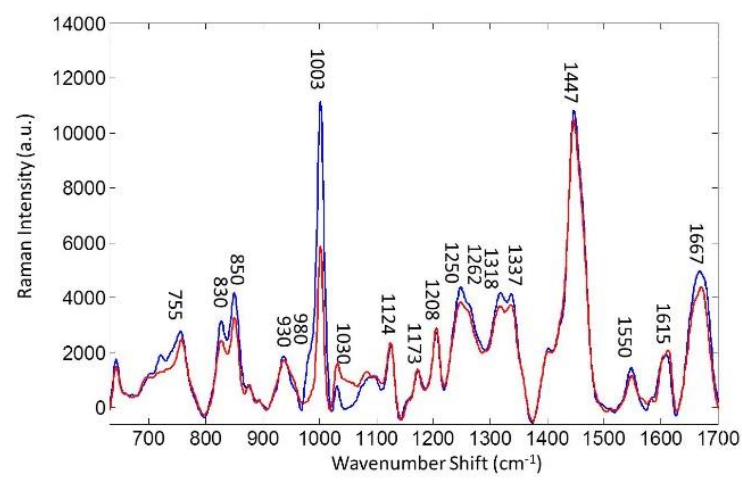

Figure 1. Averaged ( $n=3)$ Raman spectra of phosphorylated $\alpha_{s}$-casein (blue) and dephosphorylated $\alpha_{\mathrm{s}}$-casein (red). Further information on band assignments is provided in Table 1.

Table 1. Proposed Raman band assignments for phosphorylated and dephosphorylated $\alpha_{s}$-casein

\begin{tabular}{|l|l|}
\hline Wavenumber & Proposed Assignment \\
\hline $1667 \mathrm{~cm}^{-1}$ & $\beta$-sheet \\
\hline $1615-1600 \mathrm{~cm}^{-1}$ & Tyr, downward shift with protonation, minor contribution from Phe ${ }^{21,29,30}$ \\
\hline $1575 \mathrm{~cm}^{-1}$ & $\operatorname{Tyr}^{21}$ \\
\hline $1550 \mathrm{~cm}^{-1}$ & $\operatorname{Trp}^{18,22}$ \\
\hline $1460 \mathrm{~cm}^{-1}$ & Side chains, Ala, Leu ${ }^{31}$ \\
\hline $1447 \mathrm{~cm}^{-1}$ & $\mathrm{CH}_{2}$ def ${ }^{15,32}$ \\
\hline $1400-1415 \mathrm{~cm}^{-1}$ & Carboxyl stretch, ionization state ${ }^{15,29,30}$ \\
\hline
\end{tabular}




\begin{tabular}{|c|c|}
\hline $1337 \mathrm{~cm}^{-1}$ & $\operatorname{Trp}^{26} \alpha$-helix ${ }^{25}$ \\
\hline $1318 \mathrm{~cm}^{-1}$ & $\alpha$-helix ${ }^{15,25}$ \\
\hline $1262 \mathrm{~cm}^{-1}$ & $\alpha$-helix 26,29 \\
\hline $1250 \mathrm{~cm}^{-1}$ & Disordered structure ${ }^{15,27}$ \\
\hline $1234 \mathrm{~cm}^{-1}$ & $\beta$-sheet ${ }^{24}$ \\
\hline $1208 \mathrm{~cm}^{-1}$ & Tyr $^{21,32}$ \\
\hline $1173 \mathrm{~cm}^{-1}$ & $\operatorname{Tyr}^{21,32}$ \\
\hline $1124 \mathrm{~cm}^{-1}$ & $\operatorname{Trp}^{32}$ \\
\hline $1065 \mathrm{~cm}^{-1}$ & C-C stretch, Charged side chins Lys, Asp and Glu ${ }^{32,33}$ \\
\hline $1030 \mathrm{~cm}^{-1}$ & Phe $^{19,32}$ \\
\hline $1003 \mathrm{~cm}^{-1}$ & Phe $^{18,19}$ \\
\hline $980 \mathrm{~cm}^{-1}$ & Phosphate stretch ${ }^{17,28,34}$ \\
\hline $930 \mathrm{~cm}^{-1}$ & $\alpha$-helix ${ }^{15,24}$ \\
\hline $850 \mathrm{~cm}^{-1}$ & Tyr, in-plane ring-breathing motion ${ }^{20,21}$ \\
\hline $830 \mathrm{~cm}^{-1}$ & Tyr, C-H out of plane bending ${ }^{20,21}$ \\
\hline $755 \mathrm{~cm}^{-1}$ & Trp, indole ring ${ }^{18,24}$ \\
\hline
\end{tabular}

With the exception of the band observed at $930 \mathrm{~cm}^{-1}$ these invariant bands are assigned to Tyr and Trp residues reflecting that the numbers of specific residues remain consistent between phosphorylated and dephosphorylated forms of $\alpha_{\mathrm{s}}$-casein reported as 10 and 2 for bovine $\alpha_{\mathrm{s} 1}$-casein and 11 and 2 for bovine $\alpha_{\mathrm{s} 2}$-casein, respectively. ${ }^{7,35}$ The band at $930 \mathrm{~cm}^{-1}$ is assigned to $\alpha$-helix content and has not been shown to change with variations in $\alpha$-helix symmetry ${ }^{15}$ also suggesting that while the overall secondary structure content of $\alpha_{\mathrm{s}}$-casein remains consistent regardless of phosphorylation subtle changes in conformation can be determined. Interestingly, the Raman band at $1003 \mathrm{~cm}^{-1}$ assigned to Phe displays the largest difference in intensity in Figure 1 despite this peak often being assigned as invariant to conformation changes and being used for normalisation of biomolecular spectra, although more recent studies suggest that changes in intensity are associated with variations in interactions and backbone orientation around the Phe residues. ${ }^{18,19}$ As previously stated Jarvis et al. ${ }^{17}$ determined that the Raman band at $1003 \mathrm{~cm}^{-1}$ was the largest contributing peak in the quantification of phosphorylated to dephosphorylated $\alpha_{\mathrm{s}}$-casein ratios. There is a difference in the number of Phe residues in bovine $\alpha_{s 1}$-casein $(n=8)$ and $\alpha_{s 2}$-casein $(n=5)$ which may differ slightly in ratio in the phosphorylated and dephosphorylated $\alpha_{\mathrm{s}}$-casein samples available from Sigma Aldrich as exact $\alpha_{\mathrm{s} 1}$-casein: $\alpha_{\mathrm{s} 2}$-casein ratios are not determined although in bovine milk this is reported as a 4:1 ratio. The importance of the Raman band at $1003 \mathrm{~cm}^{-1}$ for quantification of phosphorylation may also be a result of its proximity to the $980 \mathrm{~cm}^{-1}$ phosphate stretch band (discussed below) which is observed as a shoulder in Raman spectrum of phosphorylated $\alpha_{s}$-casein.

The challenge of observing phosphate peaks in proteins is well documented and has previously been accredited to the presence of overlapping peptide bands in the same region as well as the lower solubility of phosphorylated proteins in aqueous solution compared to phosphorylated amino acids. ${ }^{17,36}$ However, in a previous study we successfully demonstrated that the presence of phosphate peaks at $~ 980$ and $1080 \mathrm{~cm}^{-1}$ in Raman spectra of amino acids and proteins is very much $\mathrm{pH}$ dependent. ${ }^{28}$ In Figure 1 a shoulder at $\sim 980 \mathrm{~cm}^{-1}$ can be observed for phosphorylated $\alpha_{\mathrm{s}}$-casein at a native $\mathrm{pH} 7$ whose increasing intensity is associated with the number of phosphorylated monomers in a dibasic form $\left(-\mathrm{OPO}_{3}{ }^{2-}\right)$ where the negative charge is delocalized over the three oxygen atoms. ${ }^{5,28,34}$ The phosphate peak at $1080 \mathrm{~cm}^{-1}$ is associated with the monobasic form (- 
$\mathrm{OPO}_{3} \mathrm{H}^{-}$) and therefore increases in intensity with increasingly acidic conditions. Only once highly acidic conditions $(\mathrm{pH}<2)$ are reached does stabilization of the fully protonated structure occur ($\left.\mathrm{OPO}_{3} \mathrm{H}_{2}\right){ }^{5,28,36}$ examined closely the spectra in Figure 1 do reveal a slightly broader peak at $\sim 1080$ $\mathrm{cm}^{-1}$ in the phosphorylated compared to the dephosphorylated form of $\alpha_{\mathrm{s}}$-casein, which may be associated with a monobasic phosphate stretch. However, the feature is too small to be conclusive without further investigation and is not observed in the averaged spectrum measured at $\mathrm{pH} 5.7$ (Figure 2b).

\section{Phosphorylated $\boldsymbol{\alpha}_{\mathrm{s}}$-casein 2DCOS autocorrelation}

As previously discussed the presence or absence of PTMs as well as protein protonation can significantly affect protein stability, therefore to gain a better understanding of $\alpha_{\mathrm{s}}$-casein in the different forms we carried out 2DCOS on $\mathrm{pH}$ dependent spectral data. Figure 2 displays the $\mathrm{pH}$ induced spectral data set of phosphorylated $\alpha_{s}$-casein alongside the 2DCOS autocorrelation revealing numerous spectral variations dominated by side chain and secondary structure assigned bands (Table 1). One of the challenges when analysing spectral data sets of induced transitions in proteins is determining the most important variations from what are often very complex and detailed spectra. By calculating the 2DCOS autocorrelation (Figure 2a) not only can the most significantly changing bands be identified but also the extent of variation can be directly compared across peaks. ${ }^{13,37}$

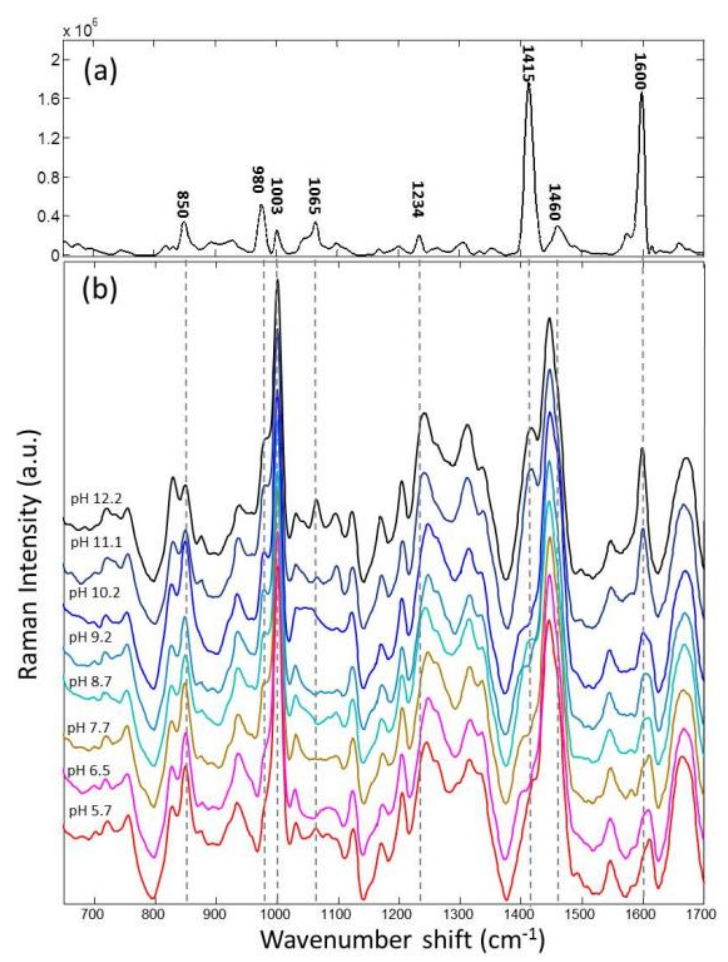

Figure 2. $\mathrm{pH}$-induced spectral variations of phosphorylated $\alpha_{s}$-casein. (a) 2DCOS autocorrelation and (b) phosphorylated $\alpha_{s}$-casein spectra acquired at solvent pH 5.7, 6.5, 7.7, 8.7, 9.2, 10.2, 11.1 and 12.2. 
From the intensity of the autocorrelation peaks in Figure 2a the largest spectral variations with changing solvent $\mathrm{pH}$ can be determined to occur at $\sim 1415$ and $1600 \mathrm{~cm}^{-1}$ followed by the peak at 980 $\mathrm{cm}^{-1}$ for phosphorylated $\alpha_{\mathrm{s}}$-casein. As expected the shoulder at $980 \mathrm{~cm}^{-1}$ can be observed to increase with increasing $\mathrm{pH}$ monitoring a change from mixed monobasic and dibasic phosphate populations to the dibasic form only. ${ }^{28,36}$ The Raman band at $1600 \mathrm{~cm}^{-1}$ is assigned to Tyr and Phe and more specifically to the deprotonation of Tyr residues whilst the $1415 \mathrm{~cm}^{-1}$ band is assigned to ionised carboxylic acid side chains (Table 1 ) and therefore also expected to vary in intensity as solvent $\mathrm{pH}$ is altered. A significant increase in intensity for both bands can be observed at $\mathrm{pH} 11.1$ and 12.2 compared to the lower $\mathrm{pH}$ values (Figure $2 \mathrm{~b}$ ). The $\mathrm{pK}_{\mathrm{a}}$ value for Tyr is reported to be $10.3 \pm 1.2$ and the dramatic increase in intensity at $1600 \mathrm{~cm}^{-1}$ above $\mathrm{pH} 10$ can be attributed to the deprotonation of Tyr residues. ${ }^{21,30}$ An additional peak in Figure $2 \mathrm{~b}$ can also be observed at $1615 \mathrm{~cm}^{-1}$ below pH 10 which disappears with increased intensity at $1600 \mathrm{~cm}^{-1}$. A shift from 1616 to $1600 \mathrm{~cm}^{-1}$ has previously been reported in Raman spectra of Tyr with increasing pH. ${ }^{21,30}$ The band at $\sim 1065 \mathrm{~cm}^{-1}$ is also assigned to changes in charged of amino acids ${ }^{32}$ and although the autocorrelation peak at 1065 $\mathrm{cm}^{-1}$ has low intensity compared to the peaks at 1415 and $1600 \mathrm{~cm}^{-1}$ the presence of distinct autocorrelation peaks does indicate a significant $\mathrm{pH}$-induced intensity change with deprotonation of phosphorylated $\alpha_{s}$-casein.

\section{Phosphorylated $\alpha$-casein PCMW}

While the autocorrelation provides useful information as to which bands vary in intensity with changing conditions it does not directly relate these spectral changes to the actual perturbation. The further 2DCOS technique PCMW overcomes this problem by directly relating the spectral transitions. ${ }^{13,14,38}$ Figure 3 displays PCMW contour plots of the $\mathrm{pH}$-induced phosphorylated $\alpha_{\mathrm{s}}$-casein plotted as a function of spectral wavenumber and the average translating perturbation, in this case $\mathrm{pH}$. In Figure 3 the largest increases in intensity (identified by the darker colour and larger number of contours) can be observed for Raman bands at 1415 and $1600 \mathrm{~cm}^{-1}$ from pH 10-12. These are consistent with the changes previously identified from the autocorrelation and the spectra (Figure

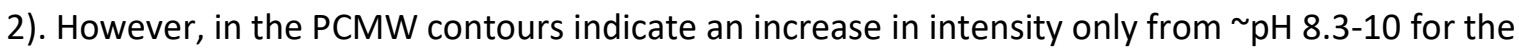
peak at $1600 \mathrm{~cm}^{-1}$, whereas for the peak $1415 \mathrm{~cm}^{-1}$ fluctuations in intensity occur throughout the full $\mathrm{pH}$ range. In Figure 3 a positive (red) contour at $980 \mathrm{~cm}^{-1}$ can be observed from pH 5.7-9 indicating the increase in the phosphate stretch assigned peak with increasing $\mathrm{pH}$, however, no contours and therefore no further significant spectral changes are determined above $\mathrm{pH}$ 9. This lack of contours suggests that all phosphates are dibasic, with the negative charge delocalised over the three oxygen atoms at $\mathrm{pH} 9$.

From a general overview of the PCMW shown in Figure 3 there appears to be two transition phases as a result of increasing $\mathrm{pH}$, and initial phase from $\mathrm{pH} \sim 5.7-9$ and a second from $\mathrm{pH} \sim 10-12$. Although contours are observed between $\mathrm{pH}$ 9-10 only one spectrum was recorded in this $\mathrm{pH}$ range and therefore these contours may be a result of small fluctuations between individual spectra, as can be seen for the Raman bands at 1065 and $1460 \mathrm{~cm}^{-1}$ in the spectra and further data at smaller pH steps are needed to confirm this potential transition phase. These fluctuations may also account for why a negative contour is observed from pH 10.5-11.5 for the Raman band at $1065 \mathrm{~cm}^{-1}$ in Figure 3 despite the fact the appearance, and therefore increase in intensity, of a distinct peak can be observed in the Raman spectra (Figure 2b). 


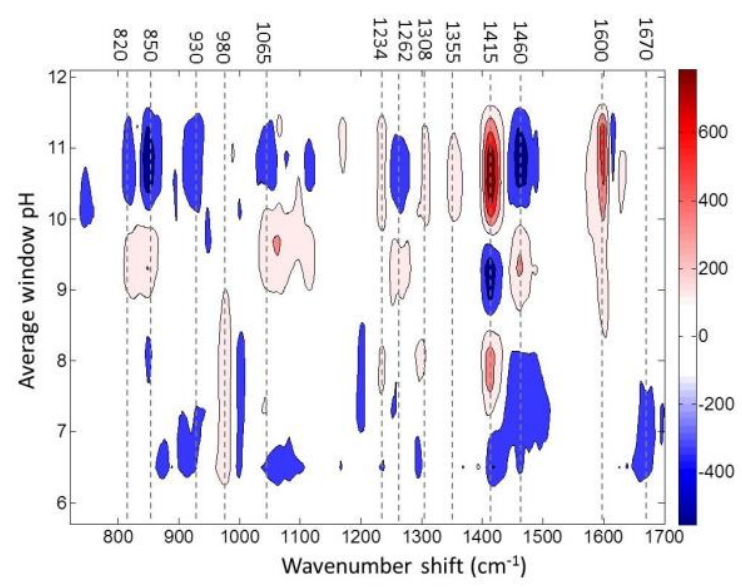

Figure 3. $\mathrm{PCMW}$ of $\mathrm{pH}$-induced phosphorylated $\alpha_{\mathrm{s}}$-casein spectral data. PCMW plotted as a function of spectral wavenumber and average translating window $\mathrm{pH}$. Contours shaded red indicate Raman bands that are increasing in intensity with increasing $\mathrm{pH}$, while blue shading indicates decreasing peak intensity with increasing $\mathrm{pH}$. The darker the shade of blue or red and the closer together the contours the greater the change in intensity, as indicated by the colour shading bar. The scale on this bar is of arbitrary units. A moving window size of 5 with a maximum of 6 contours was applied.

Despite the influence of these minor fluctuations, the lack of intensity variation in the phosphate stretch at $980 \mathrm{~cm}^{-1}$ and the increased number of contours in the second transition range compared to the first indicates that very different conformational changes occur from $\mathrm{pH} \mathrm{6-9,} \mathrm{compared} \mathrm{to}$ those that occur from pH 10-12, most likely as a result of the phosphorylated serine molecules providing protection from deprotonation of other charged side chain residues. In particular, from $\mathrm{pH}$ 10-12 decreases in intensity associated with changes in side chain environment can be determined from negative (blue) contours observed at 820, 850, 1065 and $1460 \mathrm{~cm}^{-1}$. Furthermore, decreases in Raman band intensity can also be identified from contours centred at $\sim 930$ and $1262 \mathrm{~cm}^{-1}$ both assigned to $\alpha$-helix and therefore indicating a loss of $\alpha$-helix at this $\mathrm{pH}$ range. Two positive contours can also be observed at 1308 and $1355 \mathrm{~cm}^{-1}$ despite the fact that Raman bands assigned to $\alpha$-helix are actually observed at 1318 and $1337 \mathrm{~cm}^{-1}$ (Figure 1 and 2b). In 2DCOS the most significantly changing wavenumbers do not always match to the maximum band intensity as the correlation determines the largest spectral changes which can occur as a result of shoulders and/or broadening as well as changes in maximum peak intensity. ${ }^{15}$ In Figure $2 \mathrm{~b}$ an increase in the peak at $1318 \mathrm{~cm}^{-1}$ can be observed and the two contours observed at 1308 and $1355 \mathrm{~cm}^{-1}$ in the PCMW (Figure 3) could potentially indicate a broadening of this wavenumber region suggesting a change in $\alpha$-helical structure.

Distinctive Raman bands assigned to $\beta$-structure in protein spectra are frequently observed in the regions of 1665-1670 and 1230-1245 $\mathrm{cm}^{-1}$. In Figure 3 a negative contour can be observed from $\mathrm{pH}$ 6-8 that shifts centrally from 1660 to $1670 \mathrm{~cm}^{-1}$. This upward shift is reported to indicate an increase in less ordered $\beta$-structure/ $\beta$-turns, including the possible increase in PPII structure ${ }^{30}$ suggesting conformational transitions from $\beta$-sheet to $\beta$-turn or less defined structure alongside an overall 
decrease in the total amount of $\beta$-structure with deprotonation of the phosphate serine groups. No further contours are observed in the region of $1665-1670 \mathrm{~cm}^{-1}$ with increasing $\mathrm{pH}$ although surprisingly a positive contour can be observed at $1234 \mathrm{~cm}^{-1}$ also assigned to $\beta$-sheet potentially suggesting an increase in $\beta$-sheet. Only a loss in secondary structure, not an increase, is expected to occur with deprotonation as increasing alkalinity has been reported to result in the unfolding / denaturing of casein proteins and no self-assembly or aggregation has been observed. ${ }^{11,39}$ However, when examined closely in Figure $2 b$ (and Figure 1 ) it can be determined that a Raman band is observed at $1250 \mathrm{~cm}^{-1}$ and it may be a broadening of the $1250 \mathrm{~cm}^{-1}$ band that produces the contour observed at $1234 \mathrm{~cm}^{-1}$. The Raman band at $1250 \mathrm{~cm}^{-1}$ is assigned to disordered structure ${ }^{15,27}$ and therefore an increase in intensity would be consistent with the loss a helical and $\beta$-structure as a result of increasing $\mathrm{pH}$.

\section{Dephosphorylated $\alpha$-casein autocorrelation and PCMW}

Figure 4 displays the $\mathrm{pH}$-induced spectral data set of dephosphorylated $\alpha_{\mathrm{s}}$-casein alongside the 2DCOS autocorrelation. As with the previously discussed autocorrelation (Figure 2a) spectral variations dominated by side chain assigned bands can be observed for the dephosphorylated $\alpha_{s^{-}}$ casein but relative intensities differ considerably. Whilst the peaks at 1415 and $1600 \mathrm{~cm}^{-1}$ assigned to side chain protonation still dominate in Figure 4a the peak at $1065 \mathrm{~cm}^{-1}$ is also very intense possibly suggesting increased deprotonation of Lys, Asp and Glu side chains in dephosphorylated compared to phosphorylated $\alpha_{\mathrm{s}}$-casein. As expected, the autocorrelation peak at $980 \mathrm{~cm}^{-1}$ assigned to the dibasic phosphate stretch is no longer observed. In the PCMW of the $\mathrm{pH}$-induced dephosphorylated $\alpha_{s}$-casein spectral data set (Figure 5 ) the wavenumber position of the contours is again similar to that of the phosphorylated $\alpha_{s}$-casein PCMW (Figure 3 ) but the actual position of contours with respect to $\mathrm{pH}$ is significantly different. Unlike the phosphorylated $\alpha_{\mathrm{s}}$-casein, the PCMW of the dephosphorylated form has the largest number of contours in the $\mathrm{pH}$ range 6-9. In fact, the pattern and position of contours in this lower $\mathrm{pH}$ range in Figure 5 appears similar to the contour patterns in the $\mathrm{pH}$ range 10-12 in the phosphorylated form in Figure 3 indicating that side chain deprotonation occurs at a lower $\mathrm{pH}$ in the absence of phosphate. The contours observed at $1415 \mathrm{~cm}^{-1}$ again vary in colour as $\mathrm{pH}$ is increased indicating an initial increase then decrease before a further increase in intensity. 


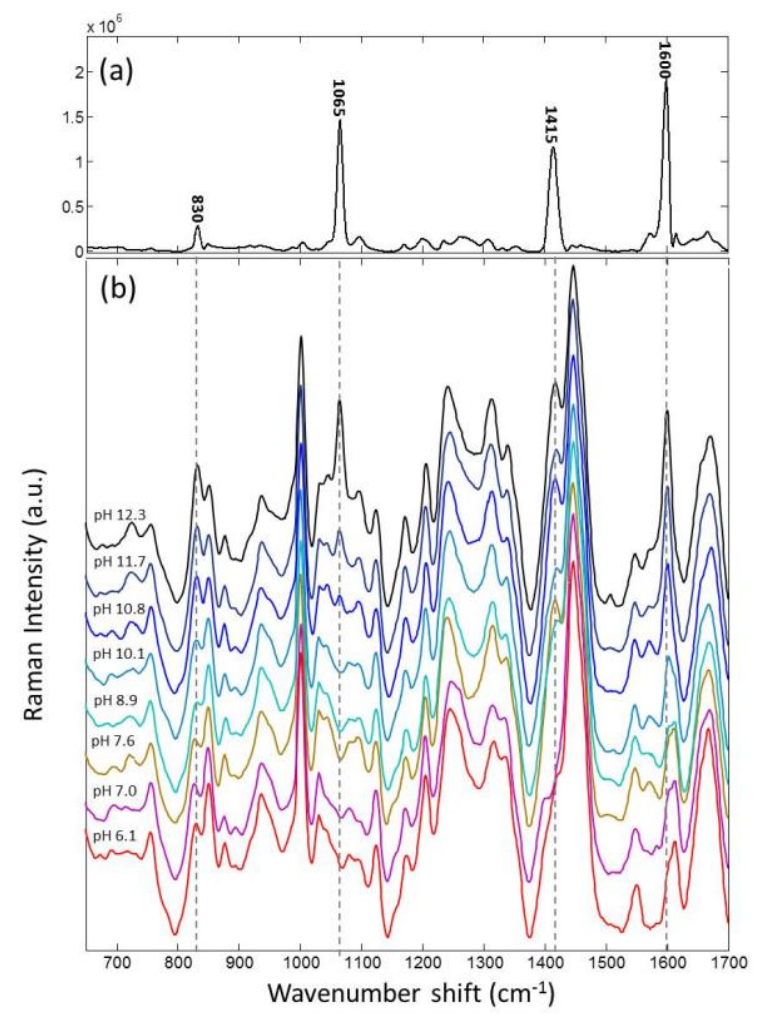

Figure 4. $\mathrm{pH}$-induced spectral variations of dephosphorylated $\alpha_{s}$-casein. (a) 2DCOS autocorrelation and (b) phosphorylated $\alpha_{s}$-casein spectra acquired at solvent pH 6.1, 7.0, 7.6, 8.9, 10.1, 10.8, 11,7 and 12.3

The PCMW plots (Figure 3 and 5) demonstrate the sensitivity of Raman spectroscopy combined with 2DCOS for determining even subtle structural changes in protein stability as a result of protonation and PTM. As previously discussed, in both forms of $\alpha_{s}$-casein the deprotonation of side chain molecules can clearly be determined with increasing $\mathrm{pH}$, however this occurs at a much lower $\mathrm{pH}$ (pH 6-9) in the dephosphorylated $\alpha_{s}$-casein compared to the phosphorylated $\alpha_{s}$-casein where changes are observed from $\mathrm{pH}$ 9-12. This shielding effect of the additional phosphate groups may also influence the loss of $\alpha$-helical structure indicated by intensity changes in the Raman bands in the region of $1308-1355 \mathrm{~cm}^{-1}$ and at $1262 \mathrm{~cm}^{-1}$ which also occur at a lower $\mathrm{pH}$ in the dephosphorylated $\alpha_{s}$-casein compared to phosphorylated. Interestingly, the $\alpha$-helical Raman band at $930 \mathrm{~cm}^{-1}$ can be observed to decrease in intensity across the full $\mathrm{pH}$ range for both forms of $\alpha_{\mathrm{s}}$-casein and therefore this loss of secondary structure occurs regardless of phosphate deprotonation. Further Raman bands where the response to increasing $\mathrm{pH}$ is not affected by changes in phosphorylation include bands observed at $1003 \mathrm{~cm}^{-1}, 1308 \mathrm{~cm}^{-1}, 1600 \mathrm{~cm}^{-1}$, and $1670 \mathrm{~cm}^{-1}$. 


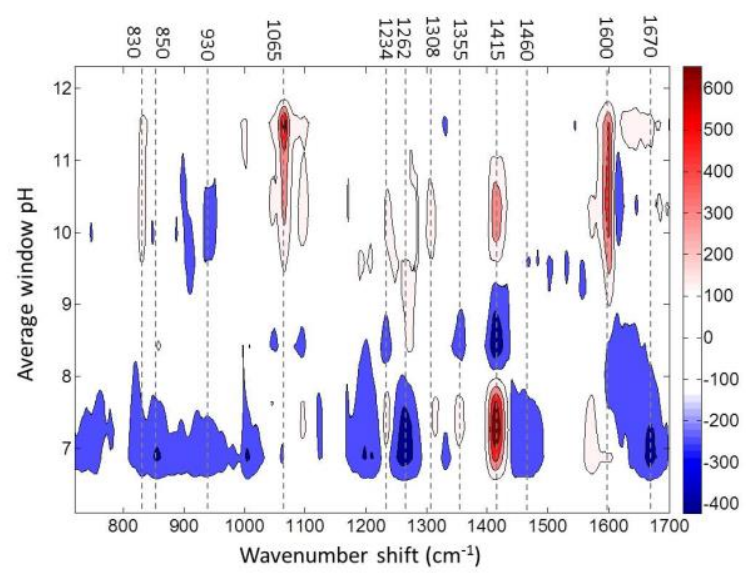

Figure 5. $\mathrm{PCMW}$ of $\mathrm{pH}$-induced dephosphorylated $\alpha_{\mathrm{s}}$-casein spectral data. PCMW plotted as a function of spectral wavenumber and average translating window $\mathrm{pH}$. Contours shaded red indicate Raman bands that are increasing in intensity with increasing $\mathrm{pH}$, while blue shading indicates decreasing peak intensity with increasing $\mathrm{pH}$. The darker the shade of blue or red and the closer together the contours the greater the change in intensity, as indicated by the colour shading bar. The scale on this bar is of arbitrary units. A moving window size of 5 with a maximum of 6 contours was applied.

A further interesting difference in response to increasing $\mathrm{pH}$ of the phosphorylated compared to the dephosphorylated $\alpha_{s}$-casein is observed in the well-established Tyr Fermi Doublet, a known marker of hydration and solvent exposure of Tyr residues. ${ }^{20,21} \mathrm{~A}$ decrease in the calculated ratio of peak intensities recorded at 830 and $850 \mathrm{~cm}^{-1}\left(\mathrm{I}_{850} / \mathrm{I}_{830}\right)$ is associated with a decrease in solvent exposure. For both the phosphorylated and dephosphorylated spectral data presented in this study a decrease in the $I_{850} / I_{830}$ ratio was observed to decrease from $\sim 1.5$ to 0.9 in both experiments with increasing $\mathrm{pH}$. However, when the spectra and 2DCOS results are examined closely very different behaviour is observed for each peak. For phosphorylated $\alpha_{\mathrm{s}}$-casein an autocorrelation peak can only be observed at $850 \mathrm{~cm}^{-1}$ (Figure 2a) which can be observed in the spectral data to increase in intensity at pH 10.2 but to decrease at $\mathrm{pH} 12.2$ compared to the more acidic $\mathrm{pH}$ range, no obvious variations can be observed for the $830 \mathrm{~cm}^{-1}$ Raman band (Figure 2b). In contrast in the dephosphorylated $\alpha_{\mathrm{s}}$-casein autocorrelation a peak is only observed at $830 \mathrm{~cm}^{-1}$ and a clear increase in Raman intensity is observed in the spectra with increasing $\mathrm{pH}$ (Figure 4). The increase in intensity of the Raman band at $830 \mathrm{~cm}^{-1}$ from pH 9 and 12 can also be clearly determined in the PCMW (Figure 5) where a positive contour is observed. No contours are observed for the peak at $850 \mathrm{~cm}^{-1}$ in this $\mathrm{pH}$ range although a negative contour is observed from $\mathrm{pH}$ 6-8. A detailed investigation of Raman markers of tyrosine by Hernández et al. ${ }^{21}$ suggests that the two bands arise from different vibrational modes, with variations in intensity of the $850 \mathrm{~cm}^{-1}$ band arising from in-plane ring breathing modes whereas 830 $\mathrm{cm}^{-1}$ corresponds to the out-of-plane $\mathrm{C}-\mathrm{H}$ bond collective motions. Consequently, it may be this very specific difference in vibrational mode of that accounts for the difference in Tyr spectral variations observed between $\mathrm{pH}$-induced changes phosphorylated and dephosphorylated $\alpha_{\mathrm{s}}$-casein. 


\section{Conclusion}

In this study we have demonstrated the unique sensitivity of Raman spectroscopy for the determination of even the most subtle of changes in protein conformation as a result of phosphorylation and deprotonation. While there is a limit to the extent of structural information that be gained from a single Raman spectrum of a protein we have shown how, vast amounts of information can be gained by comparing perturbation-induced variations in Raman spectra. By combining Raman spectroscopy with 2DCOS more detailed analysis of protein stability during bioprocessing and food manufacturing can be achieved. .

\section{Acknowledgments}

This research was funded by the EPSRC Centre for Doctoral Training in Emergent Macromolecular Therapies. The authors would like to thank the EPSRC Centre for Innovative Manufacturing in Emergent Macromolecular Therapies and Paul Dalby in the Department of Biochemical Engineering, University Collage, London for their support.

\section{Supporting Information.}

Data Processing

Water Subtraction

Normalisation

2D Correlation Interpolation

2D Calculations and PCMW

\section{References}

1. Cremades, N.; Dobson, C. M., The contribution of biophysical and structural studies of protein self-assembly to the design of therapeutic strategies for amyloid diseases. Neurobiol. Dis. 2018, 109, 178-190.

2. Lauer, T. M.; Agrawal, N. J.; Chennamsetty, N.; Egodage, K.; Helk, B.; Trout, B. L., Developability index: A rapid in silico tool for the screening of antibody aggregation propensity. Journal of Pharmaceutical Sciences 2012, 101 (1), 102-115.

3. Obrezanova, O.; Arnell, A.; de la Cuesta, R. G.; Berthelot, M. E.; Gallagher, T. R. A.; Zurdo, J.; Stallwood, Y., Aggregation risk prediction for antibodies and its application to biotherapeutic development. Mabs 2015, 7 (2), 352-363.

4. de la Cuesta, R. G.; Goodacre, R.; Ashton, L., Monitoring Antibody Aggregation in Early Drug Development Using Raman Spectroscopy and Perturbation-Correlation Moving Windows. Analytical Chemistry 2014, 86 (22), 11133-11140.

5. Wojciechowski, M.; Grycuk, T.; Antosiewicz, J. M.; Lesyng, B., Prediction of secondary ionization of the phosphate group in phosphotyrosine peptides. Biophys. J. 2003, 84 (2), 750-756.

6. Denu, J. M.; Stuckey, J. A.; Saper, M. A.; Dixon, J. E., Form and function in protein dephosphorylation. Cell 1996, 87 (3), 361-364.

7. Farrell, H. M.; Brown, E. M.; Malin, E. I., In Advanced dairy chemistry. Protein Vol 1, Basic Aspects, 4th ed.; Springer Science \& Business Media: New York, 2013; pp 84-161.

8. Koudelka, T.; Hoffmann, P.; Carver, J. A., Dephosphorylation of alpha(s)- and beta-Caseins and Its Effect on Chaperone Activity: A Structural and Functional Investigation. J. Agric. Food Chem. 2009, 57 (13), 5956-5964. 
9. Holt, C.; Carver, J. A.; Ecroyd, H.; Thorn, D. C., Invited review: Caseins and the casein micelle: Their biological functions, structures, and behavior in foods. J. Dairy Sci. 2013, 96 (10), 61276146.

10. Farrell, H. M.; Malin, E. L.; Brown, E. M.; Mora-Gutierrez, A., Review of the chemistry of alpha(S2)-casein and the generation of a homologous molecular model to explain its properties. J. Dairy Sci. 2009, 92 (4), 1338-1353.

11. Tauzin, J.; Miclo, L.; Roth, S.; Molle, D.; Gaillard, J. L., Tryptic hydrolysis of bovine alpha(S2)casein: identification and release kinetics of peptides. Int. Dairy J. 2003, 13 (1), 15-27.

12. Smyth, E.; Syme, C. D.; Blanch, E. W.; Hecht, L.; Vasak, M.; Barron, L. D., Solution structure of native proteins with irregular folds from Raman optical activity. Biopolymers 2001, 58 (2), 138151.

13. Noda, I.; Ozaki, Y., Two-dimensional correlation spectroscopy: applications in vibrational and optical spectroscopy. John Wiley \& Sons: 2005.

14. Noda, I., Vibrational two-dimensional correlation spectroscopy (2DCOS) study of proteins. Spectroc. Acta Pt. A-Molec. Biomolec. Spectr. 2017, 187, 119-129.

15. Ashton, L.; Barron, L. D.; Hecht, L.; Hyde, J.; Blanch, E. W., Two-dimensional Raman and Raman optical activity correlation analysis of the $\alpha$-helix-to-disordered transition in poly(L-glutamic acid). Analyst 2007, 132 (5), 468-479.

16. Ashton, L.; Boguslawa, C. M. B.; Blanch, E. W., Application of two-dimensional correlation analysis to Raman optical activity. Journal of Molecular Structure 2006, 799 (1-3), 61-71.

17. Jarvis, R. M.; Blanch, E. W.; Golovanov, A. P.; Screen, J.; Goodacre, R., Quantification of casein phosphorylation with conformational interpretation using Raman spectroscopy. Analyst 2007, 132 (10), 1053-1060.

18. Ota, C.; Noguchi, S.; Nagatoishi, S.; Tsumoto, K., Assessment of the Protein-Protein Interactions in a Highly Concentrated Antibody Solution by Using Raman Spectroscopy.

Pharmaceutical Research 2016, 33 (4), 956-969.

19. Hernandez, B.; Pfluger, F.; Kruglik, S. G.; Ghomi, M., Characteristic Raman lines of phenylalanine analyzed by a multiconformational approach. Journal of Raman Spectroscopy 2013, 44 (6), 827-833.

20. Siamwiza, M. N.; Lord, R. C.; Chen, M. C.; Takamatsu, T.; Harada, I.; Matsuura, H.; Shimanouchi, T., Interpretation of the doublet at 850 and $830 \mathrm{~cm}-1$ in the Raman spectra of tyrosyl residues in proteins and certain model compounds. Biochemistry 1975, 14 (22), 4870-4876.

21. Hernández, B.; Coïc, Y. M.; Pflüger, F.; Kruglik, S. G.; Ghomi, M., All characteristic Raman markers of tyrosine and tyrosinate originate from phenol ring fundamental vibrations. Journal of Raman Spectroscopy 2016, 47 (2), 210-220.

22. Miura, T.; Takeuchi, H.; Harada, I., Characterization of individual tryptophan side chains in proteins using Raman spectroscopy and hydrogen-deuterium exchange kinetics. Biochemistry 1988, 27 (1), 88-94.

23. Takeuchi, H., Raman structural markers of tryptophan and histidine side chains in proteins. Biopolymers 2003, 72 (5), 305-317.

24. Miura, T.; Thomas, G. J., Subcellular biochmeistry, Vol 24, Protiens: Strucutre, function and engineering. Plenum Press: New York, 1995.

25. Tsuboi, M.; Suzuki, M.; Overman, S. A.; Thomas, G. J., Intensity of the Polarized Raman Band at $1340-1345 \mathrm{~cm}-1$ As an Indicator of Protein $\alpha$-Helix Orientation: Application to Pf1 Filamentous Virus. Biochemistry 2000, 39 (10), 2677-2684.

26. Liang, M.; Chen, V. Y.; Chen, H.-L.; Chen, W., A simple and direct isolation of whey components from raw milk by gel filtration chromatography and structural characterization by Fourier transform Raman spectroscopy. Talanta 2006, 69 (5), 1269-1277.

27. Ellepola, S.; Choi, S.-M.; Phillips, D.; Ma, C.-Y., Raman spectroscopic study of rice globulin. Journal of Cereal Science 2006, 43 (1), 85-93. 
28. Ashton, L.; Johannessen, C.; Goodacre, R., The importance of protonation in the investigation of protein phosphorylation using raman spectroscopy and raman optical activity. Analytical Chemistry 2011, 83 (20), 7978-7983.

29. Lord, R.; Yu, N.-T., Laser-excited Raman spectroscopy of biomolecules: I. Native lysozyme and its constituent amino acids. Journal of molecular biology 1970, 50 (2), 509-524.

30. Takeuchi, H., UV Raman Markers for Structural Analysis of Aromatic Side Chains in Proteins. Analytical Sciences 2011, 27 (11), 1077-1077.

31. Derbel, N.; Hernandez, B.; Pfluger, F.; Liquier, J.; Geinguenaud, F.; Jaidane, N.; Ben Lakhdar, Z.; Ghomi, M., Vibrational analysis of amino acids and short peptides in hydrated media. I. L-glycine and L-leucine. J. Phys. Chem. B 2007, 111 (6), 1470-1477.

32. Vohník, S.; Tuma, R.; Thomas, G. J.; Hanson, C.; Fuchs, J. A.; Woodward, C., Conformation, stability, and active-site cysteine titrations of Escherichia coli D26A thioredoxin probed by Raman spectroscopy. Protein science 1998, 7 (1), 193-200.

33. Durig, J. R.; Geyer, T. J.; Little, T. S.; Kalasinsky, V. F., Spectra and structure of small ring compunds. 48. Conformational stabilty of methylcyclobutane from low-frequency Raman data of the gas. J. Chem. Phys. 1987, 86 (2), 545-551.

34. Zhang, D.; Ortiz, C.; Xie, Y.; Davisson, V. J.; Ben-Amotz, D., Detection of the site of phosphorylation in a peptide using Raman spectroscopy and partial least squares discriminant analysis. Spectrochimica Acta Part A: Molecular and Biomolecular Spectroscopy 2005, 61 (3), 471475.

35. Horne, D. S., A balanced view of casein interactions. Current Opinion in Colloid \& Interface Science 2017, 28, 74-86.

36. Xie, Y.; Jiang, Y.; Ben-Amotz, D., Detection of amino acid and peptide phosphate protonation using Raman spectroscopy. Analytical biochemistry 2005, 343 (2), 223-230.

37. Ashton, L.; Dusting, J.; Imomoh, E.; Balabani, S.; Blanch, E. W., Susceptibility of different proteins to flow-induced conformational changes monitored with Raman spectroscopy. Biophys. J. 2010, 98 (4), 707-714.

38. Morita, S., Perturbation-correlation moving-window two-dimensional correlation spectroscopy. Applied Spectroscopy. 2006, 60 (4), 398.

39. Alaimo, M. H.; Farrell, H. M.; Germann, M. W., Conformational analysis of the hydrophobic peptide $\alpha$ s1-casein (136-196). Biochimica et biophysica Acta (BBA)-Protein Structure and Molecular Enzymology 1999, 1431 (2), 410-420. 
For Table of Contents Only

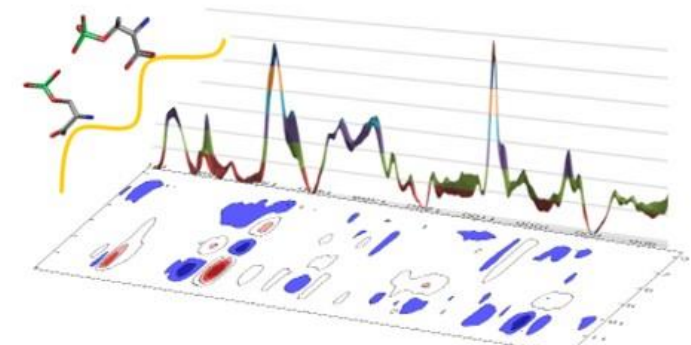

